\title{
Is Female Circumcision Driven by Culture or Poverty? Evidence from Indigenes of Ikole, Oye and Ido-Osi Local Government Areas of Ekiti State, Nigeria
}

\author{
Rufus Boluwaji Akindola, Matthew Oladipupo Abiola \\ Department of Sociology and Department of AEE, Federal University Oye-Ekiti, Oye-Ekiti, Nigeria \\ Email:Victory201811@yahoo.com, boluwaji56@gmail.com
}

How to cite this paper: Akindola, R.B. and Abiola, M.O. (2019) Is Female Circumcision Driven by Culture or Poverty? Evidence from Indigenes of Ikole, Oye and Ido-Osi Local Government Areas of Ekiti State, Nigeria. Open Journal of Social Sciences, 7 , 188-200.

https://doi.org/10.4236/jss.2019.75015

Received: October 27, 2018

Accepted: May 20, 2019

Published: May 23, 2019

Copyright ( 2019 by author(s) and Scientific Research Publishing Inc. This work is licensed under the Creative Commons Attribution International License (CC BY 4.0).

http://creativecommons.org/licenses/by/4.0/ (c) (i) Open Access

\begin{abstract}
This study investigated the relationship between Female Circumcision/Female Genital Mutilation, culture and poverty in three Local Government Areas of Ekiti State in Nigeria. Simple random sampling technique was used to select 146 respondents in three local government areas out of the 16 local government areas in the state. Primary and secondary data were used to accomplish the objectives of the study. Data were collected through the use of detailed questionnaire and focused group discussion. Descriptive statistics were applied to the data collected. The findings revealed that FC/FGM is not caused by poverty but largely by a cultural belief that has been present in these communities for centuries. The findings further confirmed that these communities are not likely to heed the ongoing global advice to discontinue the practice hence their insensitivity to the much-publicized associated risks.
\end{abstract}

\section{Keywords}

Female Circumcision, Female Genital Mutilation, Culture, Poverty

\section{Introduction}

Female circumcision (FC) or female genital mutilation (FGM) describes practices that manipulate, alter, or remove the external genital organs in young girls and women [1]. Yet [2] sees Female genital mutilation (FGM) as a form of violence against the girls and the women and also as an infringement into the rights of the women in the society. Circumcision, which has been an important African cultural practice for centuries, is more or less a household name across the continent, especially in West Africa. The birth of a new child, male or female, immediately calls for the circumcision rites to be performed. In most cas- 
es, the circumcision rites are performed within seven or eight days of the arrival of a new child. For example, circumcision among the Yoruba tribe in Nigeria traditionally occurs on the sixth day of life, and in the highlands of Ethiopia; Amhara girls are operated on shortly after they are forty days old; while in Somalia, operations are done on young girls between the ages of five and eight [3]. In extreme cases, however, circumcision rites are performed on an adult female before marriage. For example, [2] and [4] indicated that $71 \%$ of the cases of FGM were carried out at marriage among the Isoko tribes in South-South Nigeria.

The reason for female circumcision is multifaceted and varies significantly across cultures. According to [5], circumcision is often utilized to define a woman as a member of the community, or, in other words, provides women with status as well; while being uncircumcised means being labelled an outcast or an immoral woman. Correspondingly, [6] also identifies other reasons for the prevalence of circumcision such as: sexual control over females to enhance the marriageability of women; religious requirements; mythical beliefs; and the need to maintain a tradition that has been with these cultures for thousands of years. It is remarkable to note that Nigeria in the past had the highest absolute number of cases of FGM in the world accounting for about one quarter of the estimated 115 - 130 million circumcised women in the world [7]. This is echoed in a report that more than 200 million girls and women have been mutilated all over the world and that more than 20 million (10\%) of these are from Nigeria.

In the recent years, however, this age-long cultural practice has come under a renewed attack from various quarters and has been described as, not only barbaric, but also a gross violation of women and girl-child's rights. Underlying this attack is the associated health challenges presented to girls and women during and after circumcision. For example, the World Health Organisation [8] describes female circumcision as all procedures involving partial or total removal of the external female genitalia or other injury to the female genital organs for non-medical reasons. According to WHO, the removal of or damage to healthy, normal genital tissue interferes with the natural functioning of the body and causes several immediate and long-term physical, psychological and sexual consequences. Other global health and development organizations, including the Department for International Development (DFID) and US Agency for International Development (USAID), also assert that female genital mutilation and cutting is a widespread and harmful practice.

It is not surprising, therefore, that the critics of the practice have labelled it female genital mutilation (FGM) (Picture 1) in contrast to its original naming as female circumcision as widely conceptualised across Africa.

On one hand, many African countries whose ways of life are largely dictated by their traditional beliefs do not subscribe to this negative description and the relentless attack believing that female circumcision has been grossly over exaggerated by the international community. Their ground is the perceived attempt to trivialize their socio-cultural and historical values. In fact, several outspoken scholars have sharply criticized this tendency to describe female circumcision 


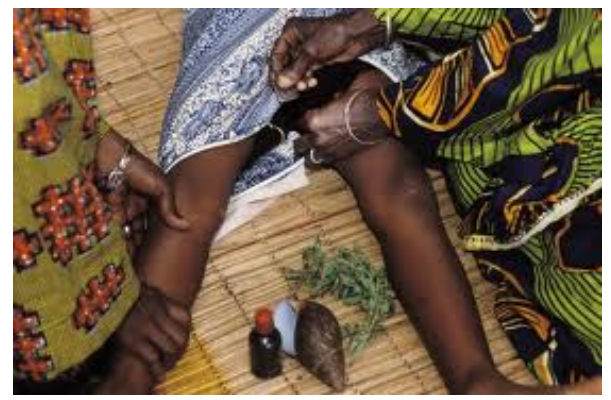

Picture 1. Female genital mutilation. Source: Vanguard newspaper (September 9, 2015).

negatively as dissocialised and ahistorical [9]. They believe that the word mutilation implies excessive judgement by outsiders and insensitivity toward individuals who have undergone the procedure.

Despite decades of programming efforts aimed at eliminating female circumcision, results have varied and in general, limited. For instance, reviews point to serious limits in the understanding of the process of decision making and change in the practice of FGM, and call for theoretical models to understand better how and why interventions cause change. Yet there are claims that female circumcision is primarily found in areas where there is much poverty, illiteracy, hunger, poor sanitary conditions. Also, its prevalence can be found where there is little in the way of health care facilities. Nonetheless, two opposing views are clearly evident in the debate over female circumcision. On the one hand, the ideological basis for the practices lie essentially in individual society's cultural, traditional, historical, economic and religious background [10]. The late founding father and former president stated that "no proper Kikuyu would dream of marrying a girl who has not been circumcised and vice versa. It is taboo for a Kikuyu man or woman to have sexual relations with someone who has not undergone this operation".

On the other hand, however, the international community sees female circumcision as involving a considerable degree of mutilation which is painful, invasive and even life threatening, and that the operation actually reduces female libido while also describing it physically as an extreme example of gender discrimination and of the domination of women by men. The bottom line is the obvious case of reclassification whereby a global concern: "female circumcision" has become female genital mutilation and a traditional practice becoming human rights violation [11]. In Uganda, an elder was quoted as denouncing "foreigners ...who call us bad names, call us primitive and call our circumcision rites genital mutilation. It makes us want to do more" [12]. Those who support and help perpetuate the practice argue that the decision to engage in such a custom is the prerogative of a society, and that other societies have no right to impose their contrary morals and beliefs. In other words, they advocate an absolute right to cultural self-determination, not even a cultural tradition, such as female circumcision, routinely resulting in death could be attacked as a violation of 
human rights.

Interestingly, the case of breast implantation which is classified as body modification in the West has inevitably been brought into the debate. Smith (2011), for example, believes that both breast implantation and female genital mutilation mold bodies into pre-existing naturalised forms. According to the author, in the United States, normal and healthy women are expected to have two proportional, ample sized, round breasts. Therefore, breast implantation is one way for women to obtain this form. In this case, the author submits that including the breast implantation in the discussion opens space for women in female genital mutilation-practicing communities to judge the practices of others, rather than to remain permanently scrutinised by Westerners. Not surprisingly, respondents of a female genital mutilation research recently conducted by Smith in Senegal communicated disbelief-disbelief that people would travel across the globe to fight female genital mutilation in foreign lands, while the horrid, unnatural, and ungodly practice of breast implantation exists back home.

Opponents of female circumcision underscore the adverse physical and emotional effects of the practice on women, young girls, and babies. Succinctly stated, they argue that a tradition that routinely harms or kills individuals is a human rights violation and should be stopped. This is based on the fact that a significant number of women and children do not have an opportunity to refuse to be subjected to this tradition. The heart of the controversy, however, lies in finding a balance between a society's cultural self-determination, and the protection of individuals from the violation of their human rights. Moreover, and as earlier indicated, female circumcision, like male circumcision, was originally an initiation rite in Africa signaling that a child was passing from puberty into adulthood thus becoming a full member of the tribe. This explains why a much higher proportion of both males and females are circumcised in Africa than in any other continent in spite of the health hazard and the ongoing public enlightenment campaigns aimed at halting the practice. It is estimated that approximately 100 - 140 million African women have undergone FGM worldwide and each year, a further 3 million girls are estimated to be at risk of the practice in Africa alone. To further illustrate the extent of the belief of African people in female circumcision, there is now a strong evidence to support the contention that the practice is being continued by Africans residing abroad. It is speculated that female genital mutilation is practiced also by immigrant communities in a number of Western countries, including Australia, Canada, France, Norway, Sweden, the UK and the USA. Migration to Sweden from FGC-practicing countries such as Somalia, Eritrea and Ethiopia in the 1980s and 1990s, for instance, has resulted in an estimated 38,000 FGC-affected women and girls living in Sweden [13]. In other words, Sweden has one of the highest prevalence figures of FGC-affected women in Europe.

\section{Methods}

It is important to recognize that factors relating to female circumcision are far 
too complex to understand from one single data source hence the utilisation of both qualitative and quantitative methods. According to [14], qualitative research has its roots in social science and is more concerned with understanding why people behave as they do: their knowledge, attitudes, beliefs and fears. On the other hand, quantitative research is concerned with counting and measuring things, producing in particular estimates of averages and differences between groups. The authors further suggest that qualitative research allows the subjects being studied to give much "richer" answers to questions put to them by the researcher, and may give valuable insights which might have been missed by any other method. In this context, not only does qualitative research provides valuable information to certain research questions in its own right but there is a strong case for using it to complement quantitative research methods.

\subsection{Questionnaire Survey}

Overall, a total of 146 questionnaires were distributed to respondents who were randomly selected across three local government areas of Ekiti State for sampling. They were Oye, Ikole and Ido/Osi Local Government Areas respectively. Table 1 shows the percentage of the respondents from the three Local Government Areas. The unreliable postal services in Nigeria and the perceived inability of respondents to fill in the questionnaires effectively without assistance were considered to be potential constraints. In order to reduce the extent of these potential constraints, questionnaires were distributed directly to each respondent in a supervised environment.

Also, each of the questionnaire items was translated to the local dialect in order to reduce the level of assistance that might be required. Nonetheless, the questionnaire survey provided quality information that was central to understanding the continued practice of female circumcision in Ekiti State. Further qualitative information was collected to complement the questionnaire. This took different forms, as it involved focus group discussions and face-to-face interviews whose participants were also randomly selected across the three local government areas.

\subsection{Study Setting}

Presently, there are 36 states in Nigeria and each of the states is important. However, the study was limited to Ekiti State because of its strong cultural belief

Table 1. The percentage of respondents from the three local government areas.

\begin{tabular}{ccc}
\hline Local Govt. Area & Frequency & Valid Percentage \\
\hline Oye Local Govt. Area & 46 & 31.5 \\
Ikole Local Govt. Area & 52 & 35.6 \\
Ido/Osi Local Govt Area & 48 & 32.9 \\
Total & $\mathbf{1 4 6}$ & 100.0 \\
\hline
\end{tabular}

Source: Field Survey 2017. 
in female circumcision. For example, Ekiti state's First Lady, Mrs. Feyisetan Fayose reported that Osun State has the highest prevalence of the circumcised women (77\%) followed by Ebonyi State (74\%) while the South-West geopolitical zone of which Ekiti is grouped under, accounts for $56.9 \%$ of the prevalent rate in Nigeria [15]. These factors provided an interesting scenario that needed to be studied. Moreover, the choice of these areas was also informed by the researcher's own rural background, especially his experience of growing up in poor conditions in neighboring Ondo State. All of these have contributed to his dedication to work towards the protection of children, the environment and poverty alleviation generally, and to the design of sensitive and innovative solutions to cultural and development problems.

\section{Results}

Following the methodological approaches outlined earlier, the results of the questionnaire survey are presented here. These are then complemented by qualitative explanations obtained from focus group discussions and face-to-face interviews. It must be noted, however, that the participation of male and female in the study varied cross the three Local Government Areas as evident in Table 2.

\subsection{The Relationship between Female Circumcision and Poverty}

It has been argued that there is a relationship between poverty and the continued practice of female circumcision, especially in Africa. For example, it was asserted that female genital mutilation is one of the manifestations of poverty if viewed through the lens of Chambers, Friedmann and Christian. Accordingly, these authors describe poverty as a state of disempowerment or the interaction of a complex framework of disempowering systems and that the household is poor in terms of assets and is physically weak, isolated, vulnerable and powerless. Yet, Djibouti's First Lady, Mrs Kadra Mahmoud Haid, said there is a strong correlation between the high prevalence of FGM/C and high levels of poverty in her country. These assertions arguably represent a much broader interpretation of

Table 2. Gender distribution of respondents.

\begin{tabular}{ccccc}
\hline & \multicolumn{2}{c}{ Gender } & Total \\
\cline { 1 - 2 } Local Govt area & Male & Female & \\
Oye Local Govt & 20 & 26 & 46 \\
& $26.7 \%$ & $37.1 \%$ & $31.7 \%$ \\
Ikole Local Govt & 28 & 23 & 52 \\
& $37.3 \%$ & $32.9 \%$ & $35.2 \%$ \\
Ido/Osi Local Govt & 27 & 21 & 48 \\
& $36.0 \%$ & $30.0 \%$ & $33.1 \%$ \\
Total & 75 & 70 & 146 \\
& $100.0 \%$ & $100.0 \%$ & $100.0 \%$ \\
\hline
\end{tabular}

Source: Field survey 2017. 
poverty given its multidimensionality. However, in the context of this study, poverty is conceptualised as lacking money.

In this case, one questionnaire item was used to measure the relationship between female circumcision and poverty. The result shows that $84 \%$ of the respondents disagreed that female circumcision is driven by poverty compared to 11 percent that answered affirmatively as evident in Figure 1. In other words, female circumcision is not driven by the desire to earn money in these communities. This was also expressed in the focus group discussions across the three local government areas as participants argued that poverty does not drive circumcision in their communities. As a result, they reported that the circumcisers are not doing it for money but because of their cultural belief and tradition which they wish to uphold at all cost.

\subsection{Understanding of Female Circumcision as Culture}

Three questionnaire items were used to measure respondents' understanding of female circumcision. The first measured understanding in terms of culture, the second in terms of social acceptability while the third measured in terms of belief system. This is evident in Figure 2 which shows that $95 \%$ of the respondents understand female circumcision as part of their culture while a tiny 5 percent believe it is not. As highlighted in the literature, some of the major reasons for the persistence of female genital mutilation in Nigerian communities are rooted in culture and tradition.

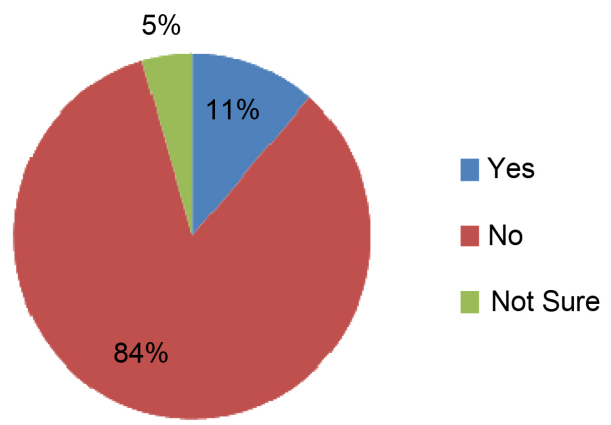

Figure 1. Distribution of respondents by poverty.

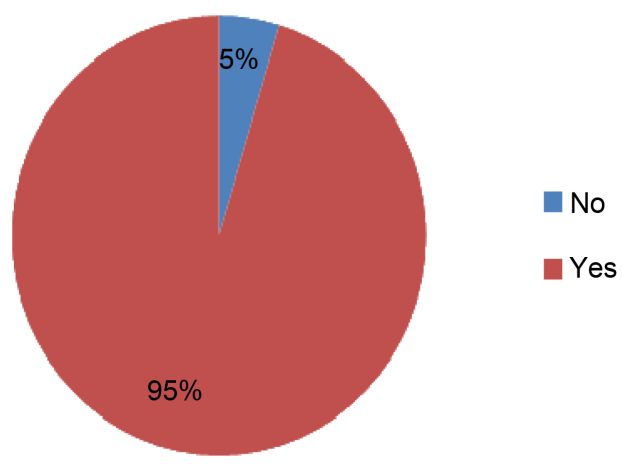

Figure 2. Distribution of respondents by understanding of female circumcision as culture. 


\subsection{Understanding of Female Circumcision as Social Acceptability}

Figure 3 indicates that $56 \%$ of the respondents understand female circumcision in terms of social acceptability compared to $44 \%$ who do not understand it along this line. It was argued that the utmost evidence of a woman is the fact that she is circumcised because the ritual practice enhances and confers social acceptability and integration upon the female. It is therefore not surprising that more of the respondents also understand female circumcision in terms of social acceptability.

Figure 4 shows that $82 \%$ of the respondents understand female circumcision in terms of belief systems compared to a tiny $18 \%$ who disagree. According to the author, FGM is often motivated by beliefs about what is considered proper sexual behaviour, linking procedures to premarital virginity and marital fidelity. In this case, the practice in many communities is believed to reduce a woman's libido and therefore believed to help her resist "illicit" sexual acts.

It is imperative to note that two of the three questionnaire items used to measure respondents' understanding of female circumcision above are significant in the sense that they are both related to cultural practices. In other words, social acceptability and belief system are just about the same thing as culture. A common theme from the focus group discussions and face-to-face interviews

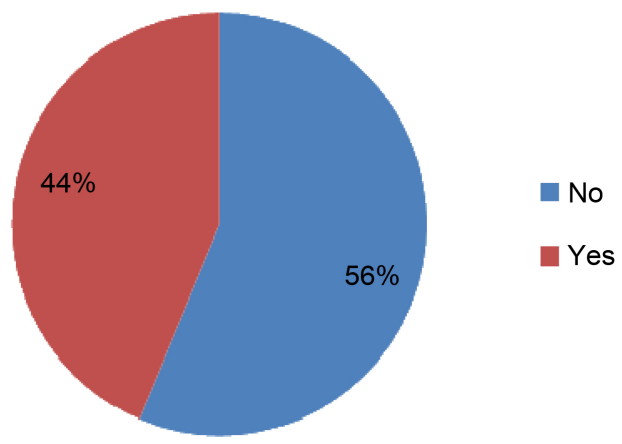

Figure 3. Distribution of respondents by understanding of female circumcision as social acceptability.

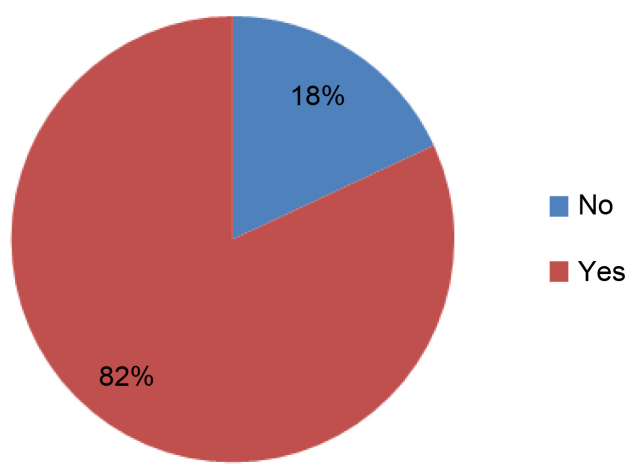

Figure 4. Distribution of respondents by understanding of female circumcision as a belief system. 
with respect to the understanding of female circumcision or FGM also revolved around cultural practices. Participants across the three local government areas consistently named culture as the principal reason for the continued practice of female circumcision. They believe that a girl cannot be considered an adult until she has undergone circumcision. For example, one of the female participants from Oye focus group stated as follows:

It is forbidden in Ekiti land not to circumcise a child, either male or female. This is our culture and we believe very strongly in the practice. My daughter was recently blessed with a baby girl in Port Harcourt, Rivers State. She brought the baby back here in Oye for circumcision.

A male participant from Oye also said:

It is a culture that has been with us for centuries and we must understand that it is dangerous for a female child not to be circumcised. The reason is that any child born by an uncircumcised woman cannot survive because once the head of the baby touches the uncut part of the clitoris, such a child is destined to die. All my female children are circumcised and by God's grace, all my grand female children will be circumcised too.

Participants from Ikole focus group overwhelmingly support the practice and its continuation. They stated that female circumcision is an important cultural practice that was handed over to them by their ancestors. As a result, they argued that it needs to be protected by all means possible. For example, one of the male participants stated as follows:

Female circumcision is our culture and our culture is quite different from white people's culture. We believe that there are serious implications if we fail to circumcise our female children.

A female participant also from Ikole focus group said:

Circumcision has been around from time immemorial. This is confirmed in the bible where Prophet Abraham was commanded by God to circumcise every male member of his household. I believe very strongly that circumcision is for both male and female and because it serves two purposes from biblical perspectives-spiritual purification and victory. That is why I personally regard circumcision of male and female children as a command from God and we must obey this.

While participants from Ido-Osi focus group also reported that female circumcision is driven by culture, a tiny proportion explained that they no longer believe in the traditional practice because of the associated health risks. They explained that their forefathers were not civilised enough to understand these risks. Moreover, the traditional ruler of Ikole-Ekiti in a face-to-face interview stated that the king must preserve the customs and traditions of Yoruba people at all times. Similarly, the traditional ruler of Ido Ekiti disclosed that his people should be free to choose what they want to do about female circumcision: "Our forefathers did it and they did not call it genital mutilation. Because white people say it is mutilation does not mean it is mutilation to us". The reactions of these 
highly respected kings suggest that female circumcision is an important part of their cultural practices and therefore must continue.

\subsection{Respondents' Understanding of Female Circumcision as Harmful}

Figure 5 shows that $67 \%$ of the respondents across the three Local Government Areas believe that female circumcision is not harmful compared to a tiny $22 \%$ who said the practice is harmful followed by $11 \%$ who are not sure. This is consistent with the findings of the focus group discussion where participants also indicated that female circumcision does not pose any risk to the health of those undergoing the procedure. They said a child does not die in the hands of the circumciser.

Figure 6 presents serious implications for the decision to continue with female circumcision/genital mutilation in spite of the obvious danger in cutting away a girl's clitoris and labia often with a crude unsterile instrument and without anesthetics by a traditional practitioner who has little knowledge of female anatomy. It also shows that the huge global campaign against the practice, as earlier stated, is not making the desired impact on the people. This is confirmed by Figure 6 as it suggests that $60 \%$ of the respondents want female circumcision to continue compared to $32 \%$ that want it stopped.

\section{Conclusion}

Female circumcision, now referred to as female genital mutilation, is widespread

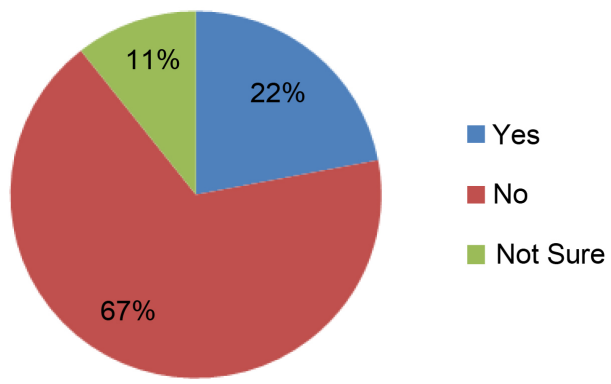

Figure 5. Distribution of respondents by harmfulness.

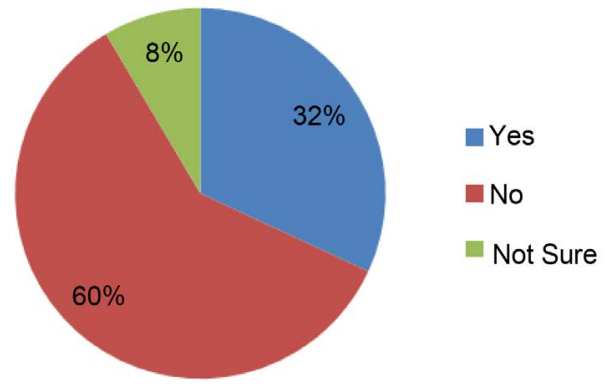

Figure 6. Distribution of respondents by continuation. 
in Africa and all efforts to eliminate it have yielded little or no result. As evident in the study findings, the practice is not motivated by poverty but largely by the culture of the people. This explains why the principal reason given by both men and women for the continuation of female circumcision across the three local government areas focused on the need to preserve tradition. Ironically, despite the adverse health implications of the practice, the people still argued that no child ever died in the hands of circumcisers and that female circumcision is their right of cultural self-determination. They believed that the risks associated with the practice can be controlled by the traditional circumcisers and that such risks have in fact been over-exaggerated by the antagonists of female circumcision. Even royal fathers who are the custodians of the people's culture and tradition do not subscribe to the pressure that female circumcision should be abolished. They, like their subjects want the practice to continue for the sole purpose of preserving their culture and tradition. This undoubtedly constitutes a major setback for the global campaign to abolish female circumcision which to the outside world is barbaric. Although some countries have resorted to legal means to either eliminate or control female circumcision, these strategies have evidently not been effective either. For example, attempts at legal prohibition in Kenya began as early as 1906 by the Church of Scotland. The Sudanese Ministry of Health launched a campaign against female circumcision and succeeded in getting a law passed that prohibited infibulation but allowed sunna. The author argues that despite these legislative efforts, all three forms of circumcision are still practiced. Furthermore, Egypt signed a resolution in 1959 recommending that only a partial clitoridectomy be performed, and then only with consent and by a physician, however, excision and infibulation are still prevalent in the country. Only recently, an Egyptian appeal court convicted a medical doctor of manslaughter and performing female genital mutilation that led to the death of a 13-year-old girl, sentencing him to two years and three months in prison. The bottom line is that female circumcision or female genital mutilation will continue for some time to come as long as the fight to end the traditional practice remains the efforts of external bodies without taking into cognisance the aspiration of the practicing communities. Arguably the options for the local people have not been sufficiently researched and at most, are significantly trivialised. The underpinning is the need for more research into the options available to the local people concerning female circumcision. Like poverty reduction efforts which require poor people's input since they are the experts of their problem, solution to female circumcision must also come from the locals rather than from outsiders who obviously have little or no understanding of local people's culture. The worst-case scenario is giving local people the opportunity to continue the practice privately without detection. This could happen if the current pressure is not inclusive of the locals and when mostly from outsiders. This has been echoed where who asserts that genital mutilation must be fought against and that the priorities and the weapons to be used in the battle must be chosen by Africans themselves, and more especially the women. 


\section{Policy Implications}

In the preceding sections of the study, critical links that constitute a major hindrance to the global campaign on the elimination of female circumcision have been highlighted. The question that arises, however, is "where do we go from here?" Firstly, it is important that the Nigerian government recognises why its past policies on the elimination of female circumcision have not been effective. An important reason is the insufficient public enlightenment programs on the danger of female circumcision as well as the lack of inclusive policies. As evident in this study, despite evidence to the contrary, female circumcision is not considered a health hazard by the majority of the people who practice it. It was argued that if the consequences of some potentially dangerous cultural operations were known in advance, the decision of individuals to proceed might well be reversed.

Secondly and finally, female circumcision cannot be completely eliminated as the practice is deeply rooted in the various communities' culture. In this case, they are more likely to resort to other crude traditional means to carry out the practice undetected. The government should therefore make the practice optional and saddle specific hospitals with the responsibility of performing such operations, especially among local people.

\section{Conflicts of Interest}

The authors declare no conflicts of interest regarding the publication of this paper.

\section{References}

[1] Frederikson, L.G., Chamberlain, K. and Long, N. (2005) Unacknowledged Casualties of the Vietnam War: Experiences of Partners of New Zealand Veterans. Qualitative Health Research, 6, 49-70. https://doi.org/10.1177/104973239600600104

[2] Awolola, O.A. and Ilupeju, N.A. (2019) Female Genital Mutilation; Culture, Religion, and Medicalization, Where Do We Direct Our Searchlights for Its Eradication: Nigeria as a Case Study. Tzu Chi Medical Journal, 31, 1-4.

https://doi.org/10.4103/tcmj.tcmj_127_18

[3] Longo, L. (1964) Sociocultural Practices Relating to Obstetrics and Gynecology in a Community of West Africa. American Journal of Obstetrics and Gynecology, 89, 470-475. https://doi.org/10.1016/0002-9378(64)90550-2

[4] Evans, D., Donahue, C., Snider, J., Bedri, N., Elhussein, T. and Elamin, S. (2019) The Saleema Initiative in Sudan to Abandon Female Genital Mutilation: Outcomes and Dose Response Effects. PLOS ONE, 14, e0213380. https://doi.org/10.1371/journal.pone.0213380

[5] Van Rossem, R. and Gage, A.J. (2009) The Effects of Female Genital Mutilation on the Onset of Sexual Activity and Marriage in Guinea. Archives of Sexual Behavior, 38, 178-185. https://doi.org/10.1007/s10508-007-9237-5

[6] Slack, A.T. (1988) Female Circumcision: A Critical Appraisal. Human Rights Quarterly, 10, 437-486. https://doi.org/10.2307/761916

[7] World Health Organisation (2010) Dynamics of Decision-Making and Change in the Practice of Female Genital Mutilation in the Gambia and Senegal. 
[8] Shell-Duncan, B. and Hernlund, Y. (2000) Female "Circumcision" in Africa: Dimensions of the Practice and Debates. Lynne Reenner Publishers, Boulder, CO.

[9] Smith, C. (2011) Who Defines "Mutilation"? Challenging Imperialism in the Discourse of Female Genital Cutting. Feminist Formations, 23, 25-46. https://doi.org/10.1353/ff.2011.0009

[10] Caldwell, C., Orubuloye, I.O. and Caldwell, P. (1997) Male and Female Circumcision in Africa from a Regional to a Specific Nigerian Examination. Social Science \& Medicine, 44, 1181-1193. https://doi.org/10.1016/S0277-9536(96)00253-5

[11] Pilt, P. (2013) Female Genital Mutilation-My Major Paper on Poverty and Development.

https://peterpilt.org/2013/09/05/female-genital-mutilationmy-major-paper-on-pove rty-and-development/

[12] Jordal, M., Griffin, G. and Sigurjonsson, H. (2018). 'I Want What Every Other Woman Has': Reasons for Wanting Clitoral Reconstructive Surgery after Female Genital Cutting-A Qualitative Study from Sweden. Culture, Health \& Sexuality, 21, 701-716. https://www.tandfonline.com/loi/tchs20

[13] Klein, E., Helzner, E., Shayowitz, M., Kohlhoff, S. and Smith-Norowitz, T.A. (2018) Female Genital Mutilation: Health Consequences and Complications-A Short Literature Review. Obstetrics and Gynecology International, 2018, Article ID: 7365715. https://doi.org/10.1155/2018/7365715

[14] The Punch Newspaper (2016) Ekiti to Enforce Law against Female Genital Mutilation.

[15] Shell-Duncan, B. and Hernlund, Y. (2000) Female "Circumcision" in Africa: Dimensions of the Practice and Debates. In: Shell-Duncan, B. and Hernlund, Y., Eds., Female Circumcision in Africa: Culture, Controversy, and Change, Lynne Rienners Publishers, Boulder, 1-40. 